\title{
O Estado e suas razões: o II PND
}

\author{
PEDRO CEZAR DUTRA FONSECA \\ SERGIO MARLEY MODESTO MONTEIRO*
}

The State and its reasons: the $2^{\text {nd }}$ PND. This paper intends to contribute to the debate on the reasons why the Geisel administration (1974-78) chose — as it faced an adverse conjuncture - an accelerated growth agenda which was materialized in the $2^{\text {nd }}$ PND (National Development Plan). In order to do so, it resorts to a methodological definition which is based upon an institutionalist approach and favors the interaction between the political and the economic variables. Contradicting the literature that interprets the strong presence of the State and the regional decentralization of the $2^{\text {nd }}$ PND as signs of neopatrimonialism, it is advocated that this category of analysis is inadequate to explain the government's choice, although this aspect is embedded in the Brazilian social-historical formation. The political rationality of the plan must be investigated in the conjuncture itself, marked by the liberalization project, which does not clash with the plan's economic rationality - on the contrary, it is complemented by it.

Key-words: Brazil, Brazilian economy, $2^{\text {nd }}$ PND, Geisel administration, political liberalization, economic development.

JEL Classification: N16.

\section{INTRODUÇÃO}

Desde que veio a público, em setembro de 1974, seis meses após a posse do presidente Ernesto Geisel, e ao longo de sua execução, o II Plano Nacional de Desenvolvimento (II PND) foi objeto de acaloradas polêmicas. Sua proposta central de imprimir novo rumo ao desenvolvimento brasileiro, ao priorizar o aumento da capacidade energética e da produção de insumos básicos e de bens de capital, re-

\footnotetext{
* Professor Titular do Departamento de Ciências Econômicas da Universidade Federal do Rio Grande do Sul - UFRGS, Brasil; Pesquisador do CNPq. E-mail: pedro.fonseca@ufrgs.br; Professor Adjunto do Departamento de Ciências Econômicas da Universidade Federal do Rio Grande do Sul - UFRGS, Brasil. E-mail: sergio.monteiro@ufrgs.br. Submetido: maio 2007; aceito: junho 2007.
} 
presentava uma guinada de vulto no modelo anterior, vigente durante o período do "milagre" de 1968-1973, cuja prioridade residia nos bens de consumo duráveis. Parecia extemporâneo e fora de propósito acelerar a economia a partir de megaprojetos, sob a forte liderança estatal, justamente quando vários países ajustavam-se, através da recessão, à nova realidade advinda da quadruplicação do preço do petróleo. Ademais, a opção por acelerar o processo de substituição de importações, explicitada no plano (Brasil, 1974, p. 37), em boa medida lembrava as teses cepalinas, combatidas pelos principais economistas do regime militar.

Os tradicionais opositores do regime denunciavam, ainda, o caráter autoritário do plano, elaborado sem prévio debate por "tecnocratas" do IPEA sob a coordenação do ministro do Planejamento, João Paulo dos Reis Velloso. Carlos Lessa $(1978$, p. 2) ilustra-os tipicamente, ao denunciar o "Estado-Príncipe", que majestaticamente "anuncia à sociedade o destino", consultando apenas as suas razões (as quais, neste trabalho, queremos contribuir para desvendar quais teriam sido). O plano materializaria a intenção de manter a ideologia do "Brasil potência", símbolo do ufanismo militarista. Na mesma linha, Maria da Conceição Tavares, em dezembro de 1976, ao analisar a conjuntura afirmou: "O PND foi sendo paulatinamente abandonado como ideologia do desenvolvimento. Nunca passou disso. Não chegou a ser um plano propriamente dito e não há no momento alternativa alguma" (Gaspari, 2003, p. 445).

Sem embargo, as discordâncias com relação ao plano rompiam com a velha polaridade entre opositores e defensores da ditadura. Delfim Netto sugeria que melhor teria sido a opção realista de enquadrar-se aos novos tempos, via diminuição do ritmo de atividade econômica. A grande imprensa, inicialmente através da revista Visão, passava a denunciar a "estatização", fato também alardeado pelo jornal O Estado de São Paulo, principalmente após ser suspensa a censura prévia ao mesmo, em janeiro de 1975. Até mesmo o ministro Mario Henrique Simonsen, da Fazenda, tendo sido questionado à época sobre o que achava do plano, teria respondido: "Não leio ficção" (Gaspari, 2003, p. 446). Finalmente, até mesmo empresários lançaram manifesto, em 1979, onde criticavam a forte presença do Estado na economia e propunham o retorno à democracia - comportamento diverso do seguido pelo empresariado desde 1964, de conivência velada ou mesmo explícita com o regime militar.

A existência de vasta gama de críticos dos mais diferentes matizes força indagar que razões levaram o governo Geisel a firmar sua opção por mudanças econômicas de tão grande envergadura, como as consubstanciadas no II PND. Inicialmente: o que teria norteado a decisão de crescimento acelerado, em detrimento do "bom senso" representado pelo ajuste? E a seguir: por que, estabelecida a escolha pelo crescimento, este recaíra em projetos de tal monta, os quais exigiam forte presença do Estado, justamente em plena crise? Enfim: qual a racionalidade do II PND?

$\mathrm{Na}$ literatura voltada a encontrar respostas para essas perguntas, ressalta-se o trabalho de Castro e Souza (1985) como a mais bem sucedida defesa do II PND. Instigados pelos expressivos saldos da balança comercial a partir de 1983, os 
quais o ministro Delfim Netto propalava como frutos de sua política recessiva, já no governo Figueiredo estes autores defenderam que os superávits deviam-se aos investimentos substitutivos de importações e em setores tradeables da época do II PND, os quais, uma vez maturados, resultaram em aumento das exportações e queda das importações, inclusive de petróleo. Segundo eles, "as escolhas de 74 conformavam uma estratégia econômica oportuna e promissora” (p. 32). $\mathrm{O}$ argumento de fundo para sustentação deste ponto de vista remete a uma interpretação do processo de industrialização de países de desenvolvimento tardio, marcado por "autênticas mutações". Estas constituem grandes blocos de investimento que ocorrem em ondas e, uma vez realizados, alteram o funcionamento da economia e elevam-na a outro patamar. Os projetos, à primeira vista, podem parecer irracionais, "inadequados, sobredimensionados, ou mesmo extravagantes” (p. 73). Entretanto, sua implementação desencadeia reações, inicialmente adaptativas e posteriormente criativas, com efeito acelerador no conjunto da economia: a conseqüência é uma mudança estrutural. Ilustram, como exemplos, o Japão após a II Guerra e, na economia brasileira, a construção da siderúrgica de Volta Redonda, no Estado Novo, bem como a introdução da indústria automobilística e eletro-eletrônica, no governo JK. As conseqüências demonstram, a posteriori, que o extravagante é agente propulsor de nova realidade; e o que parecia irracional revela-se, então, de pleno sentido.

A análise de Castro e Souza foi posteriormente contestada por Aguirre e Saddi (1997), os quais colocaram em dúvida a racionalidade econômica anteriormente assinalada, contrapondo-a à defesa de "um projeto cuja racionalidade foi politicamente determinada" (p. 79). Para tanto, recorreram ao conceito de neopatrimonialismo, de inspiração weberiana e retrabalhado por Bendix. A modernização do Estado brasileiro, a despeito de incorporar características racionais-legais, mantém estruturas de dominação tendencialmente patrimonial-burocráticas; ao lado de relações contratuais e impessoais próprias da primeira, perduram relações mais próximas de tipos tradicionais de dominação, segundo a tipologia de Max Weber. Assim, a análise das autoras busca as razões e as motivações das escolhas pelo e do II PND não nos dilemas impostos pela conjuntura, mas em raízes estruturantes do processo histórico do país. Recuperam-se, como variáveis explicativas, a centralização econômico-política e a cooptação de segmentos sociais por parte do Estado, bem como as práticas patrimonialistas e autoritárias enraizadas na política brasileira. Neste marco, o II PND não apresentaria racionalidade formal, própria da dominação legal, mas racionalidade substantiva, a qual "maximiza um conjunto determinado de objetivos independentemente de regras e regulamentos" (p. 81).

É indubitável que o trabalho de Aguirre e Saddi avança no sentido de indagar sobre as determinações políticas do plano, sem as quais, por suposto, não se pode ter uma visão minimamente acabada de seu sentido histórico. Fazem-no, todavia, de forma com a qual não compartilhamos. De imediato assinala-se uma questão de ordem metodológica, a qual diz respeito à dificuldade de se reconstituírem as motivações políticas emergentes em uma dada conjuntura restringin- 
do-se a argumentos e/ou variáveis de caráter estruturais e de longo prazo (ou, pelo menos, tendo-os como núcleo da explicação). Embora estes sejam relevantes para a reconstrução de processos históricos, é extremamente difícil, a partir deles, extraírem-se os dilemas da conjuntura, seus desafios e escolhas resultantes, sem se cair em um quase determinismo. Não se pode negligenciar o fato de que a política abarca atos volitivos e dependentes de negociação e de correlação de forças, os quais implicam opções e rearranjos, geralmente imprevisíveis e que dão margem para a criatividade e para múltiplos desfechos.

Há que se ter presente, por outro lado, a diferença do plano teórico no qual se insere a categoria racionalidade econômica, pelo menos como se depreende de seu uso feito no trabalho de Castro e Souza, e a que se tem presente ao se perscrutar a racionalidade política, se esta for associada à busca de motivos que levaram determinados atores, em certo contexto, a tomarem uma decisão. Se a racionalidade econômica pode ser detectada e desvendada ex-post, como bem demonstram Castro e Souza, não há reparo algum a fazer, do ponto de vista metodológico: muitas vezes as conseqüências de decisões de política econômica vão além das intenções dos policy-makers, e não raro logram resultado oposto aos previstos nos modelos. Todavia, o mesmo não ocorre quando a indagação diz respeito ao porquê de uma opção ter sido feita, abordagem que, em uma pesquisa, só faz sentido ex-ante, posto que independe de seus resultados. As variáveis históricas e estruturais geralmente não apagam a vasta gama de opções e de possibilidades emergentes em cada conjuntura; podem até limitá-las ou mesmo favorecer a viabilização de uma(s) delas, e geralmente o fazem, mas não têm poder de dar respostas satisfatórias, suficientes para explicar os motivos e as decisões, seja dos agentes econômicos seja dos atores políticos.

Em consonância com essa definição metodológica, assumimos que as decisões políticas que levaram o governo Geisel a optar pelo crescimento acelerado e, dentro deste, pelo II PND, devem ser buscadas, num primeiro passo, em condicionantes postos pela própria conjuntura. Isto assentado, pode-se formular duas hipóteses básicas, ambas voltadas a detectar a racionalidade do plano. A primeira afirma que o II PND e projeto de distensão política fazem parte de um mesmo processo; e, por isso, a racionalidade de cada um deles só pode ser desvendada se o outro for considerado - e, principalmente, a racionalidade política do plano, já que o projeto de distensão o antecede temporalmente, posto que anterior à própria posse de Geisel, com sua reaproximação a Golbery e com o retorno do grupo "castellista" ou "da Sorbonne", afastado do núcleo do poder com a assunção de Costa e Silva à Presidência da República. Tem-se presente que a prioridade ao crescimento econômico formulada no plano era condicionante indispensável ou facilitador para viabilizar o projeto de distensão política e ampliar a base de legitimação do regime, abalada pela crise do "Milagre". Em decorrência, não há porque se contrapor "racionalidade econômica" versus "racionalidade política", como se fossem explicações alternativas. Nossa segunda hipótese, então, propõe que ambas podem ser perfeitamente associadas para a 
reconstituição das motivações e do significado histórico do II PND, não havendo sustentação na tese que as assume como excludentes.

Passemos, inicialmente, à discussão da primeira hipótese. Para tanto, partiremos da crítica da categoria neopatrimonialismo como variável para explicar as determinações políticas do II PND. Não se trata de negá-la como importante na formação econômica e social do Brasil, mas de indagar qual seu lugar e seu alcance para explicar o objeto em foco em uma conjuntura determinada.

\section{INSTITUIÇÕES, NEOPATRIMONIALISMO E II PND}

A importância das instituições na análise econômica tem sido enfatizada nos últimos anos e parte do esforço de pesquisa tem sido dedicado a identificar os canais que conectam as instituições ao desempenho econômico. Segundo North (1995, p.1), as instituições são as regras do jogo em uma sociedade, e incluem tanto as regras formais como as informais. Williamson (2000) apresenta um esquema que ajuda a entender os possíveis níveis de análise institucional e ilustra o funcionamento da chamada Nova Economia Institucional (NEI). São quatro níveis que se conectam e apresentam efeitos de feedback.

O primeiro nível, denominado embeddedness ${ }^{1}$ por Williamson, inclui as normas, costumes, tabus, tradições e códigos de conduta. É o lugar das regras informais. A dificuldade de claramente definirem-se regras não formalizadas, bem como de testar sua relevância, faz com que, em geral, esse nível seja considerado exógeno na teoria econômica, mesmo pelos que se ocupam da análise das instituições. A idéia de embeddedness sugere a existência de elementos que constituem a matriz de longo prazo desse arcabouço analítico. O segundo nível é o ambiente institucional. Nesse encontram-se as regras formais, tais como estabelecidas por constituições e leis. O terceiro nível abriga as chamadas instituições de governança. Para Williamson, a governança é um esforço para estabelecer a ordem, reduzir conflitos e permitir a realização de ganhos mútuos. Finalmente, o quarto nível é o âmbito onde costumeiramente se delimita a análise da chamada economia neoclássica. Nesse considera-se que os ajustes de preços e quantidades ocorrem de forma contínua.

Aguirre e Saddi (1997, p. 78) propõem-se, com base no neopatrimonialismo, ${ }^{2}$ a "analisar a forma pela qual o Estado brasileiro conduziu o Segundo Plano Nacional de Desenvolvimento e, dessa forma, dar significado às decisões tomadas no período". Na forma com que foi descrito, o neopatrimonialismo é o que

\footnotetext{
${ }^{1} \mathrm{Na}$ falta de uma tradução consagrada de embeddedness, aqui se manteve a palavra em inglês.

${ }^{2}$ Segundo Schwartzman (1988), na tipologia de dominação política de inspiração weberiana há dois tipos tradicionais, o patrimonialismo e o feudalismo, e dois tipos modernos, o neopatrimonialismo e a dominação racional-legal.
} 
se poderia chamar de uma característica "estrutural" da sociedade brasileira, portanto não restrito a um período determinado de sua história econômica. Tendo como marco teórico a economia das instituições, a caracterização do neopatrimonialismo feita por Schwartzman e adotada por Aguirre e Saddi está situada no nível de embeddedness, na classificação de Williamson.

As autoras consideram que o neopatrimonialismo apresenta como característica básica o monopólio crescente do poder e dos recursos políticos e econômicos pelo centro, com conseqüências em termos de possibilidades de mudanças estruturais, definição da ordem social, promoção de políticas de bem-estar, ação de grupos de interesse e formas de mediação com esses grupos. No caso brasileiro, as crescentes demandas sociais e a incapacidade do Estado neopatrimonialista de atendê-las impelem-no a recorrer a mecanismos de cooptação, agindo sob uma racionalidade substantiva e não formal, como alternativa para evitar as crises por conflito de interesses. Nesse ponto, a análise aproxima-se da clássica de Faoro (1977, p. 748), para quem: "O poder — a soberania nominalmente popular - tem donos, que não emanam da nação, da sociedade, da plebe ignara e pobre (...) O Estado, pela cooptação sempre que possível, pela violência se necessário, resiste a todos os assaltos, reduzido, nos seus conflitos, à conquista dos membros graduados de seu estado-maior".

Para Aguirre e Saddi (1997, p. 73), a forma de dominação neopatrimonialista do Estado brasileiro e a adoção de políticas com base em uma racionalidade substantiva conferem ao II PND o caráter de um projeto "politicamente determinado". A decisão de implementá-lo apoiou-se em "motivos políticos e não puramente econômicos" o que, segundo as autoras, torna o neopatrimonialismo uma categoria relevante para a análise do período. Não há dúvidas de que "fatores" políticos são relevantes na explicação das razões da opção pelo II PND por parte do governo e que o Estado brasileiro possui as características neopatrimoniais destacadas pelas autoras. A questão a ser discutida diz respeito a que fatores teriam sido esses e ao alcance dessas características para explicar a concepção e a implementação do II PND, bem como para negar sua racionalidade econômica.

Como categoria teórica, o neopatrimonialismo pode servir para "compreender a natureza do Estado brasileiro" (Aguirre e Saddi, 1997, p. 80), mas é insuficiente para dar conta da explicação de um fato específico da história - caso contrário estaríamos admitindo implicitamente o pressuposto metodológico duvidoso de que todas as decisões conjunturais seriam explicadas a partir da estrutura, o que eliminaria o sentido das decisões políticas e das ações dos police-makers. Certamente o neopatrimonialismo traz "embutido" em si traços marcantes da formação política, econômica e social brasileira. Pode-se afirmar, parafraseando Faoro (1977, p.733), que, de D. João I aos dias atuais, "uma estrutura políticosocial resistiu a todas as tranformações fundamentais, aos desafios mais profundos, à travessia do oceano largo".

A estrutura patrimonialista mencionada por Faoro, que desemboca no neopatrimonialismo definido por Aguirre e Saddi, manteve-se ao longo do processo de formação e de expansão do capitalismo no Brasil. Assim sendo, pode-se per- 
ceber que suas características estão presentes em inúmeros momentos da história brasileira e serviriam, cum grano salis, para "explicar" não apenas a concepção e implementação do II PND, mas também o movimento de Independência, os fundamentos da República Velha, a Revolução de 1930, o surgimento e as decisões governamentais do Estado Novo, a concepção do Plano de Metas e o golpe de 1964, para ficar apenas em exemplos dos períodos que antecederam ao governo Geisel. As próprias autoras reconhecem a onipresença dessa forma de dominação ao afirmarem que "o neopatrimonialismo - conceito que tende a caracterizar melhor o Estado brasileiro, geralmente conhecido como nacional-desenvolvimentista - mostra-se como instrumento relevante para o entendimento da natureza da estrutura de dominação brasileira e, em especial, da forma como o Estado conduz a economia" (p. 94). Quer nos parecer razoável supor que se uma variável é capaz de abarcar tantas situações históricas distintas, dificilmente é a mais apropriada para explicar a particularidade e as motivações de eventos históricos específicos.

Além do mais, recorrer à "estrutura de dominação" neopatrimonialista brasileira como variável determinante para explicar a forte presença do Estado durante o período nacional-desenvolvimentista é altamente questionável, haja vista tratar-se de fenômeno presente em todos os países latino-americanos que passaram, no século XX, por processo de substituição de importações. Melhor seria considerar, como advoga a literatura clássica sobre o tema, com Prebisch e Furtado à frente, que dificilmente se poderia pensar em substituição de importações sem instituições e políticas governamentais voltadas para tal fim. Repetindo o óbvio: o intervencionismo faz parte da lógica do próprio modelo e sem ele dificilmente se pode captar e explicitar tanto sua racionalidade econômica como sua viabilidade de realizar-se como projeto historicamente determinado. Todavia, as autoras lançam mão de um critério de racionalidade a priori, a-histórico: "Ademais, no Estado racional o processo de desenvolvimento econômico mostra-se menos dependente do Estado, com maior ênfase na economia de mercado" (Aguirre e Saddi, 1997, p. 94, grifos das autoras). É inquestionável a conclusão necessariamente decorrente desta premissa: o processo de substituição de importações era irracional porque pressupunha intervencionismo, porquanto racionalidade só é possível em um estado marcadamente liberal. E, portanto, não só o II PND não possuiria racionalidade econômica e seria "politicamente determinado"- algo diferente de se falar em condicionantes políticos na reconstituição histórica -, já que se está diante de uma tese com pretensão de maior alcance, posto que formulada para abarcar várias conjunturas históricas distintas.

A partir da estratégia e dos instrumentos de ação do II PND, percebe-se que a natureza das mudanças propostas, utilizando-se a classificação de Williamson (2000), está situada no segundo e no terceiro níveis - ambiente institucional e estrutura de governança -, com efeitos, claro, sobre o quarto nível, a alocação de recursos. Nesse sentido, o neopatrimonialismo, embora presente como o "caldo de cultura" que umedece as decisões, ofusca, na análise de Aguirre e Saddi (1997), o sabor das especificidades do momento histórico. É naquilo que o pe- 
ríodo tem de singular que as explicações para a concepção e implementação do II PND devem ser buscadas. Particularmente, na conjuntura política e econômica que se segue ao "milagre econômico" e que urdiu o compromisso de Geisel com a distensão política.

\section{RACIONALIDADE POLÍTICA}

Para retomarmos as hipóteses anteriormente formuladas segundo as quais, na análise do II PND, racionalidade econômica e racionalidade política são compatíveis, bem como essa última possui raízes fundantes na própria conjuntura, um dos caminhos a trilhar remete ao problema que se tornou, durante a vigência do regime militar, sua busca permanente de legitimidade. Em termos weberianos, o que inclusive facilita o diálogo com o trabalho de Aguirre e Saddi: o fato de originar-se em um golpe de estado não o fez prescindir de pretensão de legitimidade. Ao contrário, este "vício de origem" reforça e explica sua ação nesse sentido. Ao longo de sua existência, o regime militar inúmeras vezes recorreu à força, mas jamais prescindiu da busca de elementos de coesão, ou de procurar fazer-se reconhecer como governo legítimo e, juntamente consigo, as instituições a ele vinculadas e dele decorrentes. Todo poder, como bem assinala Levi, "busca alcançar consenso, de maneira que seja reconhecido como legítimo, transformando a obediência em adesão" (In: Bobbio, 2000, p. 675).

Ao eleger Castello Branco presidente da república, em 11 de abril de 1964, o Congresso Nacional não apenas selava uma aliança entre militares e parte dos políticos civis que formaria a base de sustentação do novo regime. Mais que ato simbólico, ou capricho do marechal que buscava reconhecimento oficial para sua assunção, explicitava-se a contradição com que o regime militar iria conviver ao longo de sua existência, a qual aflora com força na conjuntura do II PND: o de ser uma ditadura cuja razão de ser consistia em "salvar a democracia”. Assim, desde seu nascedouro, as tentativas de emprestar uma face legal ao regime desvendam sua resistência de admitir-se como ditadura, posto que, no plano do discurso, esta era a principal crítica a Goulart: a tentativa deste de aprovar as reformas de base, principalmente a agrária, bem como a lei de remessa de lucros ao exterior, sem passar pelo Congresso e ao arrepio da Constituição. A bandeira da legalidade, que em 1961 respaldara a posse de Goulart, ora passava à mão de seus mais ferrenhos opositores.

O regime militar, assim, não viria para instaurar "nova" ordem (e nisso difere em muito da ideologia do Estado Novo varguista), mas para conservá-la (Fonseca, 1989, p. 288). Ao contrário dos típicos golpes de estado latino-americanos, num primeiro momento mantém o Congresso e as casas legislativas abertas, não outorga de imediato outra constituição (e quando o faz, em 1967, exige que seja votada, mantendo a capa da legalidade), não intervém no judiciário nem suspende a existência de eleições. Seria ingênuo admitir que tudo isso certamente 
decorreria de um ato volitivo ou da convicção democrática dos atores, que já haviam rompido com as normas constitucionais ao optarem pelo movimento armado para derrubar o governo, sem contar que em todos esses fatos haverá recuos ao longo da vigência do regime militar; mais realista é admitir que o regime precisava, para legitimar-se, desta aparência de legalidade. Esta lhe é constitutiva, necessária, não só para justificar-se perante a opinião pública ou a comunidade internacional, mas junto a seus próprios adeptos civis e militares: no ambiente polarizado da guerra fria, impedir o totalitarismo comunista e defender a "democracia cristã e ocidental" tornou-se o elo comum, o ponto de convergência dos revolucionários de todos os matizes, ou seja, a palavra de ordem legitimadora do golpe e o amálgama de todas as forças sociais que constituirão seu bloco de sustentação.

O governo Castelo Branco é exemplo típico desse hibridismo, ao insistir que a ditadura coexistisse com mecanismos liberais de legitimação, ou o que Weber tipifica como "racional-legal". O discurso em busca de coesão desta época tem como apelo principal a moralização e o anticomunismo, bandeiras tradicionais do udenismo; era preciso um regime de força transitório para restaurar a ordem e enterrar a "demagogia populista". Não se abandona a limine a retórica desenvolvimentista: o desenvolvimento deveria continuar a ser perseguido, mas como objetivo futuro; para alcançá-lo, fazia-se mister estabelecer como prioridade de curto prazo a estabilização. Este "sanear para depois crescer", a fórmula defendida pelo ministro Lafer no segundo governo de Vargas, ora ressurgia implicitamente no Plano de Ação Econômica do Governo (PAEG). Este assumirá como principal ponto o combate à inflação - algo que o governo anterior, "fraco", "demagógico", "populista", fora incapaz de fazer.

O novo governo tomou posse em conjuntura econômica de baixo crescimento do produto e inflação em alta, a qual contribuíra para fomentar o ambiente propício ao golpe. Porém, já nos primeiros meses, tomou a corajosa decisão de aprofundar a recessão, ao interpretar a inflação como de demanda, decorrente do aumento do déficit público e dos salários sem base em produtividade do governo anterior. Da mesma forma, Bulhões/Roberto Campos, ministros da área econômica, decidem liberar os preços represados, os quais deveriam se alinhar ao mercado, o que resultava em acelerar os índices a curto prazo, a "inflação corretiva". A opção, portanto, era aprofundar a recessão e a inflação a curto prazo, o que nos permite afirmar que nestes anos definitivamente não era o crescimento em si fonte da legitimação do regime - relegado a um aceno para o futuro, fato que aumentou a impopularidade do governo, como mostram os resultados eleitorais de 1966.

A manutenção de eleições, a despeito do regime autoritário e numa conjuntura recessiva e com inflação ascendente, tornava-se cada vez mais um jogo de difícil solução, o que contribuiu para o recrudescimento da ditadura. O governo Costa e Silva representou não só a vitória de facções políticas mais duras; do lado da economia, a entrada de Delfim Netto na pasta da Fazenda, com a interpretação de que o ajuste do lado da demanda já havia sido feito e a inflação res- 
tante era de custo - e, portanto, compatível com o crescimento, como se acreditava à época - , caía como uma luva para a cúpula militar. Só a partir daí "segurança e desenvolvimento" fará sentido como lema do regime, com a idéia de que um realimenta o outro e ambos justificam a necessidade do "regime de exceção" - expressão que traz implícito que a "regra" seria o estado de direito e cuja dubiedade para justificar a ditadura não suprime, antes revela, sua pretensão formal de legalidade. Da mesma forma, Médici, cujo governo representou a fase áurea do poder discricionário, só tomou posse após eleito pelo Congresso, que precisou ser aberto, pois fora fechado meses antes por uma junta militar. O que parte da literatura registra como uma exigência pessoal do novo presidente ajuda a revelar que a institucionalização e o que denominamos anteriormente "hibridismo" não eram meros caprichos ou formalidade, posto que recorrentes em vários episódios, pilares simbólicos e materiais do regime, e não apenas crença ideológica do chamado grupo "castellista" ou "da Sorbonne".

A definição do nome de Geisel para presidente ocorreu nos primeiros meses de 1973, ano em que o PIB cresceu 14\%, portanto no auge do "milagre". A crise do petróleo, estopim do final do ciclo de crescimento iniciado em 1968, só ocorrerá no último trimestre de 1973, período no qual o preço do barril salta de U\$ 2,90 para nível próximo a U\$ 12,00. Pesquisas em jornais (Folha de São Paulo e Correio do Povo, de Porto Alegre) e revistas da época (Veja e Visão) não permitem detectar nesta época qualquer menção ao II PND, ou a um projeto de crescimento acelerado como proposta do grupo que ascendia ao poder - e, muito menos, de um aprofundamento da substituição de importações sob a égide do Estado.

Se o II PND não existia nem como proposta, o mesmo não se pode dizer da abertura gradual do regime, a em seguida denominada "distensão". Ela não só aparece desde os primeiros pronunciamentos de Geisel como projeto consciente e deliberado, mas, como se sabe, era defendida por pessoas como Golbery, futuro chefe da Casa Civil. Em entrevista ao Centro de Pesquisa e Documentacão de História Contemporânea do Brasil (CPDOC), Geisel evidencia de forma transparente a referida consciência ao asseverar que Golbery "tinha uma cultura superior à da maioria dos oficiais do Exército. Via o Brasil de uma forma diferente. Sabia que o processo de abertura não seria fácil, que teríamos que vencer uma série de obstáculos. Era uma meta, um objetivo que tínhamos que atingir. Daí começamos a conversar, a planejar, a discutir como e quando iríamos marchar para a abertura" (D'Araujo, 1997, p.264, grifos nossos). Neste sentido, deve-se ter presente não só que os militares não formavam um bloco monolítico, mas tampouco os políticos civis que davam sustentação ao regime, e que ao lado das propostas mais radicais de "revolução permanente", consagradas no Ato Institucional $\mathrm{n}^{\circ} 5$, sempre houve iniciativas de construir um regime autoritário respaldado em eleições, com autonomia formal dos poderes e sob o império da lei. Esta utopia conservadora - na falta de uma expressão-síntese melhor - retorna com força com a ascensão de Geisel. Como bem assinala Sallum Jr. (1996, p. 2021), o impulso imediato para a liberalização do regime partiu de seu interior e o "objetivo da mudança política pretendida era atingir a 'normalização institucio- 
nal': liberalizar o regime não para superar a ordem autoritária mas para institucionalizá-la”. E, recorrendo a Juan Linz (1977, p.22): “era preciso transformar uma situação autoritária e instável, porque não consensual e baseada essencialmente na força, em regime autoritário".

A institucionalização do regime, por conseguinte, era proposta anterior ao "milagre" e a sua crise, mas foi reforçada a partir desta. Sem o crescimento que alimentava os sonhos de Brasil potência no futuro, o regime militar perdia a fonte de legitimidade que mais lhe respaldara desde o governo Costa e Silva: o crescimento. Tal fato não passou despercebido aos olhos de economistas e cientistas sociais da época. Bresser Pereira exemplifica-os de forma cristalina em artigo publicado em 04/10/1976:

“(...) este autoritarismo necessita de uma legitimação ideológica. Esta legitimação é, em geral, proposta em termos de combate à corrupção e da aceleração da taxa de crescimento do desenvolvimento econômico (...). Nestes termos, quando a taxa de crescimento da economia se desacelera, a legitimação do poder autoritário começa a esvaziar-se (...). É necessário rever políticas públicas, redefinir estratégias. Importa recuperar a legitimação perdida" (Bresser Pereira, 1987, p.43).

Fica claro, portanto, que as motivações de ordem política do II PND só são possíveis de serem desvendadas se tivermos presentes estes impasses e dilemas postos pela conjuntura. A definição pelo II PND não só foi posterior cronologicamente à opção pela distensão, como em mais de uma oportunidade Geisel enfatizou esta como seu principal objetivo. Na mensagem ao Congresso Nacional na abertura da sessão legislativa de 1975, explicitamente asseverou

“justificar, assim, a intenção manifesta, desde a primeira hora, em meu governo, de dedicar maior atenção ao campo político — não só externo como sobretudo, interno - (...) não se deixará de reconhecer a importância crítica do campo econômico, fortemente condicionante dos demais, pelos recursos que só ele lhes poderá oferecer (...), mas afirmase a prioridade instrumental do desenvolvimento político (...)" (Geisel, 1975, v. 2, p.18).

Se a legitimação do regime era um gargalo desde seu nascedouro, tornou-se problema inadiável com o fim do "milagre", fato desde logo percebido pelos novos governantes. Estes se depararão com o seguinte paradoxo: em termos ideais, o ambiente mais apropriado para a distensão e para a institucionalização seria a fase áurea do ciclo, tendencialmente mais propícia para granjear adeptos e alcançar respaldo eleitoral, como fazem crer as teorias de ciclo político oportunista; mas por que abrir o regime naquele período, se este parecia ter resolvido o problema da legitimação com o clima de euforia do "milagre"? É na crise que a falta de legitimidade se explicita com mais nitidez e transforma-se em problema cu- 
ja solução não pode ser postergada. Em síntese: o fim da expansão cíclica trazia consigo obstáculos à institucionalização, mas no velho sentido da dialética hegeliana, contraditoriamente a incitava; era ao mesmo tempo barreira e motivação da necessidade de assentar a legitimidade do regime em novas bases. Mais que velho sonho do grupo "castellista", a abertura do regime e sua institucionalização começavam a se tornar uma exigência, como captou com argúcia Bresser Pereira.

À luz desses fatos, não há como endossar Aguirre e Saddi quando interpretam como patrimonialista ou neopatrimonialista o traço essencial da legitimidade ideada pelo II PND. Como se sabe, o patrimonialismo é um tipo de dominação tradicional, enquanto a busca de legitimidade no governo Geisel era marcadamente racional-legal, ou seja, a institucionalização do regime, mesmo sem abrir mão do autoritarismo. Não se pode esquecer que legitimidade é fundamentalmente expectativa, ou seja, pretensão de reconhecimento de autoridade por parte de quem a detém. Como categorias do pensamento, à luz da metodologia weberiana, nada impede que se encontrem aspectos neopatrimonialistas em uma dominação predominantemente racional - ainda mais no caso brasileiro, ao admitirmos que tais aspectos acompanham a formação histórico-social do país e estão impregnados (embedded), em suas instituições.

Como se sabe, as ocorrências de tipos ideais são probabilísticas, no sentido de permitirem que atributos de vários deles se mesclem e coexistam numa situação histórica concreta. Cabe ao pesquisador detectar quais traços predominam, qual o tipo dominante em um caso particular. Se o tipo ideal é abstrato, o sentido que lhe dá vida só pode ser detectado empiricamente. Para tanto, no caso da legitimidade, o melhor caminho metodológico é tentar captar o sentido, a intenção da ação do governante e sua práxis em prol do desiderato visado. No contexto do governo Geisel, tal sentido, responsável por desvendar seu caráter de racionalidade como ação social, é indissociável do projeto político de distensão, o qual expressa a intenção do governo e seu empenho de legitimar-se sob uma dominação racional-legal.

\section{RACIONALIDADE ECONÔMICA}

Ao retomarmos a discussão sobre a racionalidade econômica do II PND, vale inicialmente assinalar que Aguirre e Saddi, na sustentação de seu ponto de vista, apontam duas visões sobre a mesma: a de Castro e Souza (1985), responsável por atribuir racionalidade econômica ao plano, e a de Bonelli e Malan (1976), que a questiona. Os primeiros, de fato, sustentam a idéia de que havia racionalidade econômica no II PND, embora não neguem sua natureza política. As autoras recorrem a Bonelli e Malan, entretanto, para formular sua crítica. Para tanto, defendem que estes autores, ao enfatizarem que os desequilíbrios da economia no período vão além de um problema meramente conjuntural do balanço de pa- 
gamentos, decorrente do primeiro choque do petróleo, ressaltam a importância de soluções de longo prazo que, em alguma medida, convergem com os objetivos do II PND.

Dois pontos, em especial, revelam a interpretação equivocada das autoras sobre a visão de Bonelli e Malan. O primeiro diz respeito à política de curto prazo. Segundo Aguirre e Saddi (1997, p. 87), estes "autores enfatizam, portanto, a necessidade de adoção de uma política de curto prazo para combater o déficit no balanço de pagamentos e criticam, assim, a política adotada via controle seletivo e rígido de importações". De fato, o controle de importações é considerado uma solução ad hoc por Bonelli e Malan, mas ela é parte de uma estratégia de curto prazo. Para os autores, "o desequilíbrio nas contas externas expressa e reflete um desequilíbrio estrutural pelo lado da oferta que tem uma história, e que já atingiu proporções e conseqüências que requerem reajustes deliberados na estrutura de sua economia" (Bonelli e Malan, 1976, p. 369). Ou seja, o que os autores ressaltam é a necessidade de mudanças de maior envergadura, ou de longo prazo.

O segundo ponto diz respeito a essa política de longo prazo. Para as autoras, "Bonelli e Malan, por conseguinte, questionam a "racionalidade econômica do II PND, no que se refere, em especial, à adoção de uma política de substituição de importações” (p. 87). Entretanto, o que os autores discutem não é esta opção em si, mas a "intensidade com que se deve e/ou pode seguir uma política de substituição de importações industriais” (Bonelli e Malan, 1976, p. 403). A contribuição destes é no sentido de mostrar que o problema não é apenas o de poupar divisas via substituição de importações, mas também de aumentar a produção de bens exportáveis, o que reforça, e não se choca, com a tese defendida por Castro e Souza.

Podemos agora explorar com mais acuidade a questão relacionada à racionalidade econômica do II PND. Para tanto, é preciso ter presente que as dificuldades enfrentadas para sua implementação ocorrem no mesmo contexto das verificadas para levar a cabo o projeto de distensão. Assim, ambos, distensão e II PND, como dois projetos de alteração de rumos, foram capazes de gerar resistências, muitas das quais enfrentadas, no curto prazo, reforçando o autoritarismo e o poder discricionário do Presidente da República (v. g., o "pacote de abril" e as mudanças no alto comando militar para viabilizar a candidatura do Gen. Figueiredo para lhe suceder), que outorga a si o papel de mediador e a palavra final na solução dos conflitos. Não é de estranhar, neste sentido, os recuos e avanços do projeto político, os quais lhe aparentam certa dubiedade ou vacilação, tantas vezes denunciados à época por seus opositores. Sem embargo, esses também são verificáveis na área econômica, seja na composição da equipe (Reis Velloso, no Planejamento, e Severo Gomes, na Indústria e Comércio, mais afinados com o nacionalismo e com a prioridade ao crescimento do II PND, e Simonsen, na Fazenda, mais ortodoxo e preocupado com a estabilidade), seja no próprio stop and go, o qual sugere o dilema entre crescimento e estabilidade num período de inflação ascendente, como sugere o Gráfico 1. Sem contar o próprio cres- 
cimento da inflação, com a generalização da indexação, a qual expressa a exacerbação do conflito distributivo, tão explorado pela teoria inercialista, cujo desenvolvimento ganhou impulso justamente a partir dessa época.

Gráfico 1: Brasil: Crescimento do PIB e Inflação (IGD-DI), 1973-1979

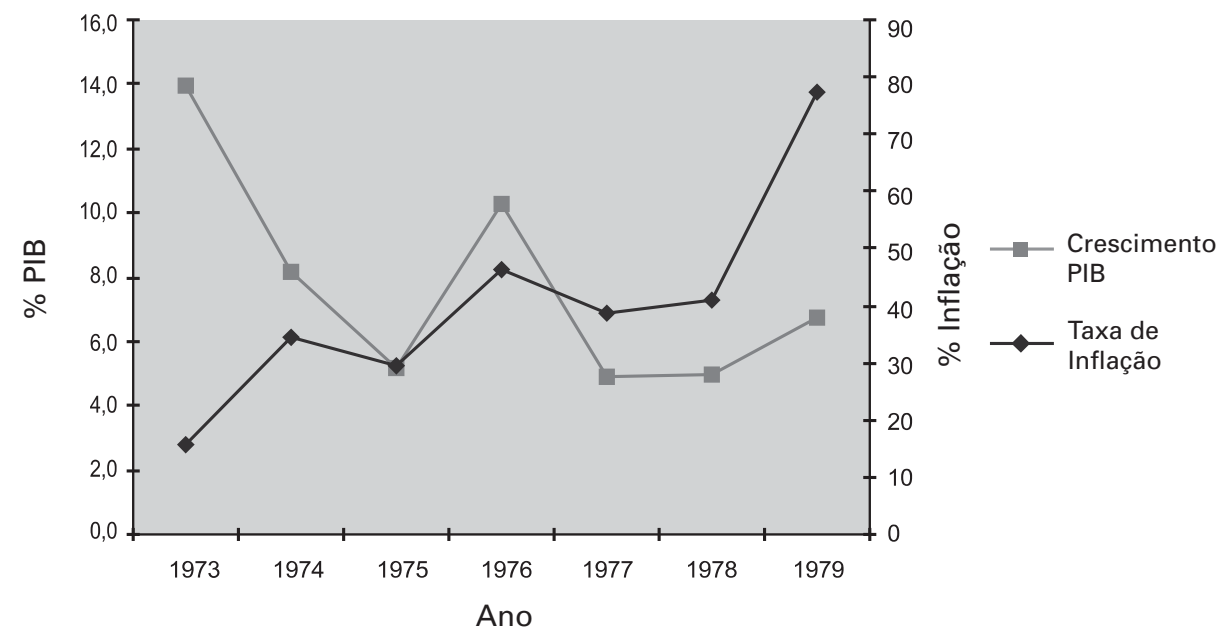

A complexidade e a envergadura das propostas do II PND remetem ao questionamento de como se pretendia viabilizá-lo politicamente. À primeira vista, poder-se-ia esperar que a distensão não o favorecesse, ao criar um ambiente mais propício para aflorar antagonismos e explicitar divergências. A descentralização espacial dos investimentos presente no plano é geralmente apontada como uma forma de cooptar as "oligarquias regionais" para galgar seu apoio. Para Aguirre e Saddi, esta tentativa de procurar sustentação em outros segmentos, como nos políticos civis, através da diversificação de investimentos regionalmente, confirmaria sua hipótese relativa ao neopatrimonialismo, pois o governo tenderia "a agir de acordo com os 'grupos de interesses' cooptados, ou seja, com base numa racionalidade substantiva, em detrimento da racionalidade formal" (Aguirre e Saddi, 1997, p. 82, grifos nossos). Este é, ao nosso ver, o esteio central da tese das autoras para questionar a racionalidade econômica do II PND e sustentar, em contraposição, o fato de ter sido "politicamente determinado".

Ao recorrermos a outra linha de interpretação, é preciso deixar claro, inicialmente, que quanto ao caráter "estatizante" e à descentralização espacial dos investimentos do II PND terem favorecido o compartilhamento do poder por parte do centro político com segmentos regionais não há reparos a fazer. Mas não se tratava de fenômeno novo, posto que perfeitamente verificável pelo menos desde 1930, para não remontar ao Império, prática usual durante a vigência de todo o processo de substituição de importações, tipicamente ilustrada pelo Estado Novo. Seria isto alguma novidade que pudesse auxiliar no encontro de alguma evi- 
dência empírica para reforçar uma legitimidade (neo)patrimonialista e marcar a historicidade do II PND?

Para responder essa pergunta, nada melhor do que se retomar a fonte teórica das próprias autoras: Max Weber. Para este, a ação social determinada de modo racional referente a fins orienta-se por expectativas quanto ao comportamento de outras pessoas, "utilizando essas expectativas como 'condições' ou 'meios' para alcançar fins próprios, ponderados e perseguidos racionalmente, com sucesso" (Weber, p. 15). A ação racional não só possui objetivos e valores claramente formulados e consistentes, mas busca os meios mais adequados para perseguilos. Neste aspecto, se o objetivo era a institucionalização do regime, como leválo a cabo sem o apoio do Congresso, instituição cujos membros majoritariamente deveriam dar guarida ao projeto e eram imprescindíveis para assegurar a governabilidade ao Executivo? Como pensar em distensão política sem respaldo parlamentar? Justamente por ter pretensão de legitimidade racional-legal, o governo não poderia prescindir de sustentação política, ainda mais quando se tem presente a forte resistência de segmentos militares ao projeto político governista (v. g., a demissão de Frota). A tese de perceber como "cooptação" e dominação tradicional a descentralização dos investimentos subestima justamente o propósito, a expectativa da ação do governo: a pretensão da legitimidade racional-legal. ${ }^{3}$

Assim, entendemos que também não há como sustentar a tese de que a descentralização regional do II PND deve-se a uma cooptação de caráter típico da dominação patrimonialista, já que "das principais características das dominações de tipo patrimonial é a lealdade, pois a cooptação leal não apresenta caráter racional: pelo contrário, ela ocorre de forma incondicional e, por isso, possui características patrimoniais, ou melhor, neopatrimoniais". Ou, ainda, que se tratava de neopatrimonialismo porquanto se verificava "um processo de acomodação, de forma que esses grupos não pretendem sair do governo" (Aguirre e Saddi, 1997, p. 83). Ora, a literatura política sobre esse período é rica em enumerar os inúmeros dissensos, e principalmente dentro do bloco de sustentação do governo, a começar pela resistência à distensão, a campanha empresarial contra a "es-

\footnotetext{
${ }^{3}$ Velloso (1998, p. 135), optou por outro caminho para defender a pretensão de legitimidade racionallegal: a preocupação e as ações de Geisel no sentido de gerir o Estado por regras impessoais e burocrático-legais: "nessa época se alcançou o máximo de institucionalização legal das funções econômicas e sociais do Estado (...). De outro lado, nesse período, as diferentes formas de patrimonialismo haviam chegado a seu nível mais baixo". Este procedimento foi desconsiderado por Aguirre e Saddi (1998, p.147): "Portanto, não é suficiente elencar todos os esforços realizados pelos vários governos brasileiros no intuito de burocratizar, no sentido weberiano, a administração pública, para demonstrar a característica não patrimonial deste Estado". É indubitável que patrimonialismo e burocratização do Estado podem coexistir, até porque a dominação patrimonialista, na tipologia, recorre a quadro administrativo, mas parece-nos contraditório negar que critérios e práticas de administração burocrático-legais dificultam, e não reforçam, a ocorrência de práticas patrimonialistas e clientelísticas.
} 
tatização" e o discurso nacionalista de Severo Gomes, estopim para sua exoneração do cargo ministerial.

Interpretar o II PND como um processo de "acomodação" acaba por negligenciar completamente sua proposta política de institucionalizar o regime e, mais grave do ponto de vista econômico, de redirecionar completamente a prioridade da economia com a alteração de projetos de investimento, bem como com planos de implantação de novas plantas produtivas e financiamento de outras atividades, diferentes das que vinham sendo mais de perto contempladas, contrariando interesses e grupos consolidados. Isto significava acenar para novas alianças, romper com o estabelecido, ou, como bem expressam Castro e Souza (1985, p. 74):

Percebe-se também que o tipo de mudança de que estou tratando não atende e nem pretende atender aos interesses econômicos imediatos. Requer, pelo contrário, um relativo descondicionamento face à situação presente. Este descondicionamento pode ser facilitado pela erupção de crises capazes de por a nu a vulnerabilidade do status quo. Não menos importante é, porém, a vontade política de superar a crise, via transformação.

Essa observação de Castro e Souza chama atenção para o fato de o plano ter como objetivo maior manter as taxas de crescimento econômico e, para isso, entendeu que se fazia mister alterar os rumos do desenvolvimento brasileiro. Esta é, em síntese, sua racionalidade econômica. Há que se ter claro, neste sentido, a distinção entre elaboração e implementação de qualquer instrumento de planejamento, ou, no caso, entre as razões que levaram o governo a elaborar o plano e suas propostas com relação ao uso político que dele foi feito quando de sua implementação. Neste sentido, o neopatrimonialismo diz mais respeito a este último e menos com relação aos motivos que levaram ao diagnóstico e às propostas consubstanciadas no plano. Como dizem estes últimos autores, a vontade política está em "superar a crise," e para tanto foi elaborado um diagnóstico realista da economia brasileira (aliás, fortemente apoiado na metodologia estruturalista cepalina), o qual concluía pela necessidade de um pacote de investimentos. Este decorre do referido diagnóstico e não da necessidade de cooptação dos políticos regionais; não se trata de uma "irracionalidade" patrimonialista, a qual subentende a inversão da relação de causalidade e define que a cooptação política tenha sido a variável determinante das decisões. ${ }^{4}$

\footnotetext{
${ }^{4}$ Em resposta à crítica de Reis Velloso (1998, p. 133), Aguirre e Saddi (1998, p.147) assim se manifestaram sobre como deveria ser uma argumentação sólida voltada a demonstrar a característica nãopatrimonialista do Estado à época do II PND, ou seja capaz de contrapor-se a sua tese: "Seria necessário demonstrar que não é possível estabelecer qualquer relação entre II PND e o Pacote de Abril de 1977, que sugere uma relação entre apoio político dos estados do Nordeste e o rol de investimentos do II PND, na forma como foi apontada no artigo. Assim como explicar a impossibilidade de
} 
É verdade que a decisão e o ato de planejar são sempre imbuídos e permeados de motivações políticas - mas isto não pode apagar sua racionalidade econômica. Caso contrário, não haveria razão de existir planejamento, por definição uma proposta de construção do futuro com pretensões de racionalidade, ou seja, explicitando objetivos, metas e os meios mais adequados para viabilizá-las. Nibil novi sub sole. Destarte, não se pode esquecer que a descentralização regional dos investimentos não pode ser explicada apenas por determinações políticas, por mais que estas fossem importantes, haja vista a própria prioridade do plano: a alteração da matriz energética e os insumos básicos. Ora, ao contrário do crescimento induzido pelo setor de bens duráveis de consumo verificado no período de JK ao "milagre", que requeria como fatores atrativos de localização mão de obra qualificada e mercado consumidor, portanto o eixo São Paulo-Rio de Janeiro, os novos ramos dependiam, como fatores locacionais determinantes, de fontes de matérias-primas, recursos minerais e hídricos. Estes são por natureza "descentralizados", ou seja, disseminados pelo território nacional. São os casos de minérios de ferro de Carajás (Pará), Itaipu (Paraná), carvão (Santa Catarina e Rio Grande do Sul), petróleo (bacias do nordeste e Rio de Janeiro), fertilizantes potássicos (Sergipe), soda de cloro/sal-gema (Alagoas) e fosfato (Minas Gerais), dentre outros.

Por isso é precipitada a inferência de que a série de investimentos descentralizados espacialmente do II PND possa ser reduzida a uma intenção de prebenda ou decorrente de mera prática de cooptação, aos moldes (neo)patrimonialistas. Seu uso político ex-post - algo "normal" no ritual dos governos, mesmo democráticos -, não pode ser interpretado como seu fator indutor por excelência. Não se pode esquecer que a referida descentralização decorria de outra, mais geral e que se materializava como diagnóstico central do plano, sua marca arrojada e inovadora: a crise energética não era temporária nem conjuntural, mas estrutural, e daí requerer alteração dos rumos do padrão de desenvolvimento e o incremento do processo de substituição de importações, a despeito das adversidades. E esta racionalidade econômica não colide, antes reforça, sua racionalidade política, qual seja, criar ambiente necessário para implementar o projeto de distensão gradual do regime.

relacionar o crescimento econômico do período, a manutenção e elevação da taxa de juros interna e o endividamento externo, que apontam para uma interligação entre II PND e setor financeiro nacional. E, finalmente, explicitar a inexistência de relação entre II PND e os investimentos em infra-estrutura regional, que, por sua vez, sugere interligação entre empreiteiras e II PND". Claro que se a questão for colocada sabiamente nestes termos poucos reparos restam a se fazer. Porém, o que está em pauta não é "relacionar" e "interligar”, algo sempre possível entre variáveis econômicas e políticas. O que está em discussão é a relação de causalidade e as motivações dos atores políticos e dos agentes econômicos. $\mathrm{Ou}$, em termos weberianos, ao gosto das autoras: a ação social determinada de modo racional referente a fins. 


\section{CONCLUSÃO}

À luz do exposto, podemos afirmar que os dados empíricos por nós trabalhados referentes à conjuntura do II PND apontam na direção de corroborar as hipóteses formuladas na introdução deste trabalho. Não há dúvidas de que o II PND é um plano "políticamente determinado", se por isto se entender seus condicionantes políticos - no caso, principalmente o fato de ter sido formulado e implementado em um contexto no qual o governo que ora assumia presenciava o fim do "milagre brasileiro" e, com ele, inviabilizava-se a retórica da busca de coesão através do expressivo desempenho da economia. O plano, neste aspecto, prestava dupla colaboração: alentava a possibilidade de manter o crescimento e, ao mesmo tempo, contribuía para propiciar um clima favorável às mudanças políticas pretendidas, consubstanciadas no projeto de distensão política. Este acenava para a legalização do regime autoritário através de mecanismos de dominação racional, com a adoção de regras formais do estado de direito, proposta que vinha desde 1964 e ora ganhava impulso com o fim do "milagre" e a ascensão do novo governo.

Desta forma, as tradicionais práticas (neo)patrimonialistas, embedded na formação histórico-social brasileira, como demonstra a análise inspirada no marco institucionalista, certamente estão presentes em aspectos da formulação e na implementação do II PND, mas não constituem sua busílis. Esta é, fundamentalmente, sua pretensão de legitimidade formal-legal, que pode probabilisticamente coexistir com práticas de dominação tradicional, mas não constituem sua marca, sua razão de ser, seu sentido como ação social. Fica claro, na análise da conjuntura, que esta remete à expectativa de construção de uma dominação de caráter racional.

Com isto não se quer dizer que o II PND não tenha apresentado problemas de execução e de financiamento, jogando parte de seu custo ao futuro, com impacto nas dívidas interna e externa, bem como na inflação, como defende certa parte da literatura. Racionalidade, no caso, significa que o plano se assentava em um diagnóstico da economia brasileira, explicitava seus impasses estruturais e conjunturais e, a partir deles, fundamentava a necessidade de executar um conjunto de investimentos. Havia consistência interna entre o referido diagnóstico e suas propostas. Havia consistência externa, qual seja, do plano em si com o contexto nacional e internacional, sob a percepção de que a crise não era passageira e que o problema energético era duradouro e estrutural. Não se tratava de mera retomada do crescimento, mas de redirecionar os rumos da industrialização brasileira, ao priorizar a industrialização pesada, os tradeables e a alteração da matriz energética, cujo impacto na estrutura do balanço de pagamentos nos anos seguintes parecem inquestionáveis. Certamente estava permeado de condicionantes políticos, como qualquer ato de planejamento, mas estes em nada ferem sua racionalidade econômica. 


\section{REFERÊNCIAS BIBLIOGRÁFICAS}

Aguirre, Basilia e Saddi, Fabiana da C. (1997) "Uma alternativa de interpretação do II PND”. Revista de Economia Política, 17(68): 78-98.

. (1998) “A fantasia política ou a política da fantasia?”. Revista de Economia Política, 18, 2 (70): 145-47. Disponível em http://www.rep.org.br

Boarati, Vanessa (2005) “A defesa da estratégia desenvolvimentista - II PND”. História Econômica e História de Empresas, São Paulo, v. VIII-I.

Bobbio, Norberto et alii (2000) Dicionário de Política. Brasília/São Paulo: Ed. Universidade de Brasília/Imprensa Oficial do Estado de São Paulo. $5^{\text {a }}$ ed.

Bonelli, R. e Malan, P. (1976) "Os limites do possível: notas sobre o balanço de pagamentos e indústria nos anos 70”. Pesquisa e Política Econômica, Rio de Janeiro, 6 (2).

Brasil (1974). II Plano Nacional de Desenvolvimento (1975-79). Brasília: Imprensa Oficial.

Bresser-Pereira, Luís Carlos (1978) O Colapso de uma Aliança de Classes. São Paulo: Brasiliense.

Carneiro, D. D. (1989) “Crise e esperança: 1974-1980". In: Abreu, M. de P. (org.) A Ordem do Progresso. Rio de Janeiro: Campus.

Castro, A. B. de e Souza, F. (1985) A Economia Brasileira em Marcha Forçada. São Paulo: Paz e Terra.

Correio do Povo, Porto Alegre, jul/1973 - jan/1976.

D’Araujo, Maria Celina e Castro, Celso (org.) (1997) Ernesto Geisel. Rio de Janeiro: Editora Fundação Getúlio Vargas.

Faoro, Raymundo (1977) Os Donos do Poder: Formação do Patronato Político Brasileiro. Porto Alegre: Globo.

Fonseca, Pedro Cezar Dutra (1989) Vargas: O Capitalismo em Construção. São Paulo: Brasiliense.

Gaspari, Hélio (2003) A Ditadura Derrotada. São Paulo: Companhia das Letras.

Geisel, Ernesto (1975, 1976, 1977, 1978) Discursos. Brasília: Assessoria de Imprensa e Relações Públicas da Presidência da República, 4 v.

Lessa, Carlos (1978) A Estratégia de Desenvolvimento 1974-76. Sonho e Fracasso. Rio de Janeiro (Tese).

Linz, Juan (1977) "The future of an authoritarian situation or the institucionalization of an authoritarian regime: the case of Brazil". In: Stepan, Alfred (ed.) Authoritarian Brazil. New Haven: Yale University Press.

North, Douglass (1995) Institutions, Institutional Change and Economic Performance. Cambridge: Cambridge University Press.

O Estado de S. Paulo, São Paulo, jul/1973 - dez/1975.

Revista Veja, jul/1973 - dez/1975.

Revista Visão, jul/1973 - dez/1975.

Saddi, Fabiana da Cunha (2003) "Política e economia no federalismo do governo Geisel". Revista de Economia Política, 23, 2 (90): 28-46. Disponível em: http://www.rep.org.br/pdf/90-2.pdf

Sallum Jr., Basílio (1996) Labirintos: Dos Generais à Nova República. São Paulo: HUCITEC.

Schwartzman, Simon (1988) Bases do Autoritarismo Brasileiro. Rio de Janeiro: Campus. Disponível em: http://www.schwartzman.org.br/simon/. Acesso em 28/08/2006.

Sola, Lourdes (1998) Idéias Econômicas, Decisões Políticas. São Paulo: Edusp/Fapesp.

Velloso, João P. dos Reis (1998) “A fantasia política: a nova alternativa de interpretação do II PND”. Revista de Economia Política, 18, 2 (70): 133-144. Disponível em: http://www.rep.org.br/pdf/ 70-9.pdf

Weber, Max (1999) Economia e Sociedade; Fundamentos de Sociologia Compreensiva. Brasília/São Paulo: Ed. Universidade de Brasília/Imprensa Oficial do Estado de São Paulo.

Williamson, Oliver (2000) "The new institutional economics: taking stock, looking ahead". Journal of Economic Literature, vol. 38: 595-613. 